\title{
Development of a Model for Prediction of Solar Radiation
}

\author{
W. D. A. S. Wijayapala and D. H. K. Kushal
}

\begin{abstract}
Power generation from renewable energy sources such as wind, mini-hydro, solar etc is becoming increasingly popular due to environmental concerns. However, it is not possible to predict the energy generation of solar power plants in advance. Hence the power system operator has no information about the tomorrow's possible energy availability from these non-dispatchable power plants. The outcome of this study enables the system operator to predict the possible energy generation from solar power plants based on the weather forecasts and provide the system operator with predictions on energy generation and capacity of solar power plants connected to the grid. The predictions will enable to prepare the dispatch schedules accordingly.
\end{abstract}

In this study, the effect of the geographical and meteorological parameters for predicting daily global solar radiation at Sooriyawewa, Hambantota in Sri Lanka is investigated. A multiple linear regression was applied to explain the relationship among solar radiation and identified meteorological and geographical parameters such as cloud cover, sunshine duration, precipitation, open air temperature, relative humidity, wind speed, gust speed and sine value of declination angle. Variables in these equations were used to estimate the global solar radiation. Values calculated/predicted from models were compared with the actual measurements to validate the model.

Keywords : $\quad$ Solar Power, Solar Radiation, Prediction

\section{Introduction}

Power generation from renewable energy sources is becoming popular all over the world. Sri Lanka, a developing country located close to the equator, should consider solar energy as a source of power generation to the nation. Due to the geographical location close to the equator, solar radiation is abundantly available throughout the year in most parts of the country. Therefore, proper utilization of this resource would be beneficial both economically and environmentally.

Measurements of solar radiation are important in developing solar energy devices to supplement existing energy sources. This is of particular importance for a country like Sri Lanka where the sunshine is available in abundance. There are also other uses for such information in quantitative ecological studies as the source of energy used in photosynthesis and evapotranspiration. The solar radiation climatology of the world has been extensively studied by numerous workers in the past. However, since solar radiation reaching the earth's surface depends on factors such as cloud cover and turbidity which are not global in nature, on-site radiation data are essential.
The most important usage of this model is that it can be used to predict the future solar

radiation available for power generation using weather forecast data. Then the electricity dispatch control centre of the country can use this information when preparing their future dispatch schedules.

The accurate information of solar radiation intensity at a given location is essential to the development of solar energy-based projects and in the evaluation of the solar energy conversion systems' long-term performance. This information is used in the design, in financial analysis, and in the efficiency calculations of a project. Furthermore, monthly mean daily data are needed for the estimation of solar power system's energy generation. Sri Lanka as a country located in the equator belt has the opportunity to utilize solar energy effectively, promoting a clean environment, and developing renewable energy technologies in the country. The use of photovoltaic devices,

\footnotetext{
Eng. W.D.A.S Wijayapala, BScEng(Hons) (Moratuwa), MEng(Moratuwa), Int.PEng(SL), CEng, FIE(Sri Lanka), Senior Lecturer, Department of Electrical Engineering, University of Moratuwa.

Eng. D.H.K. Kushal, BScEng (Hons) (Ruhuna), MSc (Moratuwa), AMIE(Sri Lanka), Electrical Engineer, Central Enoineering Consultancu Bureau.
} 
on the other hand, is suitable for rural electrification, water pumping, telecommunication towers, solar thermal devices, etc. Given these many possible uses of solar energy, it is important to know the global solar radiation distribution throughout the year for interested regions.[1]

Even though the climate of the country is most favourable for solar energy utilization, the distribution of the solar radiation is not well known. The most important parameter for solar energy applications is the average global solar radiation of which measurements are not available at every location.

In places where no measured data are available, a common application has been to determine this parameter by appropriate correlations which are empirically established using the measured data. Several empirical models have been used to calculate solar radiation, utilizing available meteorological, geographical and climatological parameters such as sunshine hours, air temperature, latitude, precipitation, relative humidity, and cloudiness. Models to estimate solar radiation based only on sunshine hours are available for Sri Lanka.

The main objectives of this study is determination of factors affecting the solar radiation reaching the earth's surface and development of a model to predict solar radiation based on the identified parameters of which forecasts are available.

In order to achieve the main objective, the following methodology was formulated.

- Identification of the parameters that affect the solar irradiance.

- Collecting data on the parameters that are measured in Sri Lanka.

- Performing Regression analysis.

- Obtaining a model to predict solar radiation.

- $\quad$ Validating the proposed model.

\section{Methodology}

Monthly average daily global solar radiation data is essential in the design and study of solar energy conversion devices. For this purpose there are some proposed models for Sri Lanka by researchers. Many of the models developed to estimate solar radiation are based on the sunshine hours. Sunshine hour data recorded in a number of weather stations all over the country for a fairly long period of time is available with the meteorological department of Sri Lanka. Other than that agricultural research centres also maintain records of sun shine hours. Availability of data records for a longer time period is very much important for researches of this nature.

In order to propose a model to predict solar radiation, it is necessary to identify the factors that affect the solar radiation that would be available on earth's surface. [2] [3] Factors affecting Solar Radiation

- Distance from the sun.

- Duration of daily sunlight period.

- Solar elevation or inclinations of the solar rays to the horizon.

- Transparency of the atmosphere towards heat radiation

- Output of solar radiation.

The first three of these factors are intimately connected with revolution of earth. It is to be noted here that the earth revolves about the sun in an elliptic orbit and makes one complete revolution in 365 days; simultaneously it spins about itself and complete one rotation in every 24 hours. The average distance to earth from the sun is 149.5 million $\mathrm{km}$. The duration of daylight also varies with the latitude and season. Longer the daylight duration, greater is the insolation received [4].

Several empirical models to estimate solar radiation are found in literature and those models utilize available meteorological, geographical and climatological parameters such as sunshine hours, air temperature, latitude, precipitation, relative humidity, and cloudiness [5].

The most commonly used parameter for estimating global solar radiation is sunshine duration. It is obvious that sunshine duration is a parameter which indicates the amount of solar radiation available at the earth's surface rather than a factor that affects the radiation reaching the earth's surface.

Parameters such as relative humidity, precipitation, wind speed, and gust speed can cause impacts on the atmosphere through which the radiation reaches the earth's surface. The presence of clouds in the sky is very common in Sri Lanka throughout the year. Sri Lanka being closer to the equator where the trade winds tend to converge causing development of low pressure cells helps the 
formation of clouds. When clouds are present, water droplets effectively absorb the energy from downward radiation. Thus, inclusion of cloud cover data as an explanatory variable to the model for cloud transmittance is necessary to achieve better predictions.

Since the declination angle $(\delta)$ explains the sun's location in the sky, it affects the amount of solar radiation available to a particular location of the earth at a particular time[4][6].Therefore, the sine value of the declination angle (sin $\delta$ ) is taken as an explanatory parameter in the model proposed in this study.

Declination Angle $(\delta)$ can be defined as follows (Duffie and Beckman, 1991):

$$
\delta=23.45 \sin \left(360 \frac{284+n}{365}\right)
$$

Where, $\mathrm{n}=$ Julian day of the year

\section{Data collection}

The daily data for computations were collected from July 2011 to December 2012 for Hambantota, Sri Lanka. Data for Solar Radiation, Sunshine Duration, Cloud cover, Precipitation, Ambient Temperature, Relative Humidity, Wind Speed, Gust Speed were collected from Meteorological Department(MD)of Sri Lanka and from an existing Solar Power Plant (SPP) at Hambantota where regular measurements are made.

Table 1 - Data for Hambantota and collected source

\begin{tabular}{|c|c|c|}
\hline $\begin{array}{l}\text { Parameter/Measure } \\
\text { ment }\end{array}$ & Source & $\begin{array}{l}\text { Available } \\
\text { Period }\end{array}$ \\
\hline $\begin{array}{l}\text { Solar Radiation }(\mathrm{H}), \\
\mathrm{MJ} / \mathrm{m}^{2}\end{array}$ & SPP & $\begin{array}{l}\text { Jul } 2011 \text { to } \\
\text { Dec } 2012\end{array}$ \\
\hline Cloud Cover (C), \% & MD & $\begin{array}{l}\text { Jul } 2011 \text { to } \\
\text { Nov } 2012\end{array}$ \\
\hline $\begin{array}{l}\text { Sunshine Hours (n), } \\
\mathrm{h}\end{array}$ & MD & $\begin{array}{l}\text { Jul } 2011 \text { to } \\
\text { Oct } 2011 \text { \& } \\
\text { Feb } 2012 \text { to } \\
\text { Aug } 2012\end{array}$ \\
\hline $\begin{array}{l}\text { Precipitation (p), } \\
\text { mm }\end{array}$ & SPP & $\begin{array}{l}\text { Jul } 2011 \text { to } \\
\text { Dec } 2012\end{array}$ \\
\hline $\begin{array}{l}\text { Open Air Temp. } \\
\left(T_{a}\right),{ }^{\circ} C\end{array}$ & SPP & $\begin{array}{l}\text { Jul } 2011 \text { to } \\
\text { Dec } 2012\end{array}$ \\
\hline $\begin{array}{l}\text { Sine value of } \\
\text { Declination Angle } \\
(\sin \delta),{ }^{\circ}\end{array}$ & Calculated & $\begin{array}{l}\text { Jul } 2011 \text { to } \\
\text { Dec } 2012\end{array}$ \\
\hline
\end{tabular}

\begin{tabular}{|l|c|l|}
\hline $\begin{array}{l}\text { Relative Humidity } \\
(\mathrm{r}), \%\end{array}$ & MD & $\begin{array}{l}\text { Jul } 2011 \text { to } \\
\text { Dec } 2012\end{array}$ \\
\hline $\begin{array}{l}\text { Wind speed (W), } \\
\mathrm{m} / \mathrm{s}\end{array}$ & SPP & $\begin{array}{l}\text { Jul } 2011 \text { to } \\
\text { Dec } 2012\end{array}$ \\
\hline $\begin{array}{l}\text { Gust speed }(\mathrm{G}), \\
\mathrm{m} / \mathrm{s}\end{array}$ & SPP & $\begin{array}{l}\text { Jul } 2011 \text { to } \\
\text { Dec } 2012\end{array}$ \\
\hline
\end{tabular}

In order to find a model to estimate the solar radiation, selected eight parameters are considered as explanatory variables. Then, investigations were made to find relationship between those parameters and the solar radiation. For this purpose multiple linear regression analysis was performed. In the process of applying multiple linear regression, out of eight parameters, one variable is selected and came out with eight equations $\left.{ }^{8} C_{1}\right)$ for the selected explanatory variable.

Similarly, two variables are selected out of the eight parameters and twenty eight $\left({ }^{8} C_{2}\right)$ numbers of equations are obtained. This process is repeated for $3,4,5,6,7$ and 8 number of variables.

In the above process total of $255\left({ }^{8} \mathrm{C}_{1}+{ }^{8} \mathrm{C}_{2}+\right.$ $\left.{ }^{8} C_{3}+{ }^{8} C_{4}+{ }^{8} C_{5}+{ }^{8} C_{6}+{ }^{8} C_{7}+{ }^{8} C_{8}\right)$ number of equations are obtained [7] [8].

In mathematics, the coefficient of determination, denoted by $R^{2}$ is a number that indicates how well data fit a statistical model. Out of the 255 equations, model with the highest $\mathrm{R}^{2}$ value is selected as the best model which explains the solar radiation reaching the earth's surface.

The parameter, maximum Gust Speed (G) is not easily available as a forecast or a measurement. Therefore, in addition to the 8 variable model, seven other models are selected again based on higher $R^{2}$ values avoiding G.

\section{Comparison Techniques}

There are numerous research in literature which deal with the assessment and comparison of the daily solar radiation estimation models. The most popular statistical parameters are the Mean Bias Error (MBE) and the Root Mean Square Error (RMSE). In this study, to evaluate the accuracy of the estimated data from the models described above, statistical tests on MBE, RMSE and Mean Percentage Error (MPE) were carried out. For better data modelling, these statistics should be closer to zero. The Nash- 
Sutcliffe equation (NSE) was also selected as an evaluation criterion. A model is more efficient when NSE is closer to 1 . However, these estimated errors provide reasonable criteria to compare models but do not objectively indicate whether a model's estimates are statistically significant. The tstatistics allows models to be compared and at the same time it indicates whether or not a model's estimate is statistically significant at a particular confidence level. Therefore t-test of the models were also carried out to determine statistical significance of the predicted values by the models. [5] [12]

\subsection{Mean Bias Error}

$$
\operatorname{MBE}=\frac{1}{\mathrm{n}} \sum_{1}^{\mathrm{n}}\left(\mathrm{H}_{\mathrm{i}, \text { calc }^{-}} \mathrm{H}_{\mathrm{i}, \text { meas }}\right)
$$

Where $\mathrm{H}_{i \text {,meas, }} \mathrm{H}_{\mathrm{i} \text {,calc }}$ are the $\mathrm{i}^{\text {th }}$ measured value and $i^{\text {th }}$ calculated value of daily solar radiation. $\mathrm{n}$ is the number of data pairs.

This test provides information on long-term performance. A low MBE value is desired. A negative value gives the average amount of underestimation in the calculated value. One drawback of this test is that overestimation of an individual observation will cancel underestimation in a separate observation.

\subsection{Mean Percentage Error}

$\operatorname{MPE}(\%)=\frac{1}{\mathrm{n}} \sum_{1}^{\mathrm{n}}\left(\frac{\mathrm{H}_{\mathrm{i}, \text { calc }}-\mathrm{H}_{\mathrm{i}, \text { meas }}}{\mathrm{H}_{\mathrm{i}, \text { meas }}}\right) * 100$

A percentage error between $-10 \%$ and $+10 \%$ is considered acceptable.

\subsection{Root Mean Square Error}

$$
\operatorname{RMSE}=\left(\begin{array}{cc}
\frac{1}{\mathrm{n}} & \sum\left(\mathrm{H}_{\mathrm{i}, \text { calc }}-\mathrm{H}_{\mathrm{i}, \text { meas }}\right)^{2} \\
\mathrm{n} & 1
\end{array}\right)^{1 / 2}
$$

The value of RMSE is always positive, representing zero in the ideal case. The normalized root mean square error gives information on the short term performance of the correlations by allowing a term by term comparison of the actual deviation between the predicted and measured values. The smaller the value, the better is the model's performance.
3.4 Nash-Sutcliffe Equation

$$
\mathrm{NSE}=1-\quad \frac{\sum^{\mathrm{n}}\left(\mathrm{H}_{\mathrm{i} \text { meas }}-\mathrm{H}_{\mathrm{i}, \text { calc }}\right)^{2}}{\mathrm{n}\left(\mathrm{H}_{\mathrm{i} \text {,meas }}-\overline{\mathrm{H}_{\text {meas }}}\right)^{2}}
$$

Where $\overline{\mathrm{H}_{i}}$,meas is the mean measured global radiation and $\mathrm{n}$ the number of data pairs. A model is more efficient when NSE is closer to 1.

\section{5 t-Statistic Test}

t-statistic is defined as (Walpole and Myers, 1989)

$$
\mathrm{t}=\left(\frac{(\mathrm{n}-1)(\mathrm{MBE})^{2}}{(\mathrm{RMSE})^{2}-(\mathrm{MBE})^{2}}\right)^{1 / 2}
$$

The smaller the value of $t$, the better is the performance of the model.

\section{Development of the Models}

As mentioned earlier, multiple linear regression analysis was performed to find the relationship between selected parameters to the solar radiation.

The response variable is set as solar radiation $(\mathrm{H})$ and the other variables as sunshine hours $(n)$, cloud cover $(C)$, precipitation $(p)$, open air temperature $\left(\mathrm{T}_{\mathrm{a}}\right)$, sine value of the declination angle $(\sin \delta)$, relative humidity $(\mathrm{r})$, wind speed $(W)$, gust speed $(G)$ as explanatory variables. Out of the many models developed, following 8 models were found to be with acceptable accuracy levels as validated in the following sections.

- Model 1 - H versus $C, n, p, T_{a}, \sin \delta, r, W, G$

$\mathrm{H}=-19.3-0.0413 \mathrm{C}+0.645 \mathrm{n}-0.0480 \mathrm{p}$

$+1.53 \mathrm{~T}_{\mathrm{a}}-4.88 \sin \delta-0.0596 \mathrm{r}-0.029 \mathrm{~W}+0.114$

G

- Model 2 - $H$ versus $C, n, p, T_{a}, \sin \delta, r, W$

$\begin{aligned} \mathrm{H}= & -19.3-0.0389 \mathrm{C}+0.662 \mathrm{n}-0.0396 \mathrm{p} \\ & +1.54 \mathrm{~T}-4.91 \sin \delta-0.0588 \mathrm{r}+0.169 \mathrm{~W}\end{aligned}$

- Model 3 - $H$ versus $C, n, p, T_{a}, \sin \delta, r$

$\mathrm{H}=-21.0-0.0374 \mathrm{C}+0.664 \mathrm{n}-0.0440 \mathrm{p}$

$+1.61 \mathrm{~T}_{\mathrm{a}}-4.49 \sin \delta-0.0529 \mathrm{r}$ 
- Model 4 - $H$ versus $C, n, p, T_{a}, \sin \delta, W$

$\mathrm{H}=-22.3-0.0401 \mathrm{C}+0.662 \mathrm{n}-0.0435 \mathrm{p}+1.49$ $\mathrm{T}_{\mathrm{a}}-5.43 \sin \delta+0.155 \mathrm{~W}$

- Model 5 - $\mathrm{H}$ versus $C, n, T_{a}, \sin \delta, r, W$

$\mathrm{H}=-21.5-0.0381 \mathrm{C}+0.672 \mathrm{n}+1.64 \mathrm{~T}_{\mathrm{a}}-5.07$ $\sin \delta-0.0696 r+0.193 W$

- Model 6 - $H$ versus $C, n, \sin \delta, p, T_{a}$

$\mathrm{H}=-23.6-0.0386 \mathrm{C}+0.664 \mathrm{n}-0.0472 \mathrm{p}+1.56$ $\mathrm{T}_{\mathrm{a}}-4.99 \sin \delta$

- Model 7 - $H$ versus $C, n, T_{a}, \sin \delta, r$

$\mathrm{H}=-23.7-0.0364 \mathrm{C}+0.673 \mathrm{n}+1.73 \mathrm{~T}_{\mathrm{a}}-4.58$ $\sin \delta-0.0643 r$

- Model 8 - $H$ versus $C, n, \sin \delta, T_{a}$

$H=-27.1-0.0379 C+0.673 n+1.68 T_{a}-5.20$ $\sin \delta$

The statistical performance of developed models was investigated by using MBE, MPE, RMSE, NSE, t- statistic and $\mathrm{R}^{2}$ and the results are summarized in Table 2.

Table 2 - The results of statistical analyses of models

\begin{tabular}{|c|c|c|c|c|c|c|}
\hline & & & & & & \\
\hline $\begin{array}{l}\frac{\bar{d}}{8} \\
\frac{0}{z}\end{array}$ & 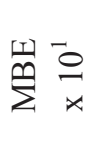 & $\sum_{\Omega}^{\sqrt[N]{\mathscr{N}}}$ & + & $\underset{\widetilde{d}}{\stackrel{0}{a}}$ & 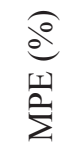 & $\begin{array}{ll}\sqrt{1} & 0 \\
\mathrm{Z}^{2} & \\
x\end{array}$ \\
\hline 1 & 1.06 & 2.292 & 0.770 & 69.5 & 2.20 & 6.94 \\
\hline 2 & -0.11 & 2.298 & 0.077 & 69.3 & 1.64 & 6.93 \\
\hline 3 & 1.17 & 2.307 & 0.843 & 69.1 & 2.26 & 6.90 \\
\hline 4 & -0.33 & 2.303 & 0.235 & 69.1 & 1.54 & 6.91 \\
\hline 5 & -1.00 & 2.307 & 0.098 & 69.0 & 1.62 & 6.90 \\
\hline 6 & 1.00 & 2.310 & 0.721 & 69.0 & 2.19 & 6.89 \\
\hline 7 & 0.40 & 2.316 & 0.284 & 68.8 & 1.88 & 6.88 \\
\hline 8 & 0.80 & 2.322 & 0.573 & 68.6 & 2.09 & 6.86 \\
\hline
\end{tabular}

\section{Validating the models}

This study developed models to predict the solar radiation using eight explanatory variables. Using the models it is possible to estimate today's (Day number 1) solar radiation using today's measurable explanatory variables and also to predict tomorrow's (Day number 2) solar radiation using today's predictions for tomorrow's explanatory variables. Similarly, it is possible to predict day after tomorrow's (Day number 3) radiation using today's predictions on day after tomorrow's explanatory variables. Then, tomorrow (on day number 2) one can compare the predicted figure with the actual and also predict the radiation for day number 3 based on day number 2's data. On day number 3 one can compare the actual value with predicted radiation values predicted based on both day number 1 and day number 2.Comparison of actual and predicted radiation values in $\mathrm{MJ} / \mathrm{m}^{2}$ are shown in Table 3 to Table 10 for the developed models.

Table 3 - Validation of the model 1 with 8 variables $\left(C, n, p, T_{a}, \sin \delta, r, W, G\right)$

\begin{tabular}{|c|c|c|c|c|}
\hline 莺 & 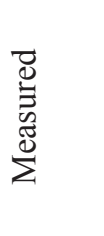 & 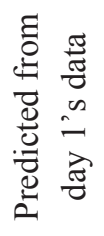 & 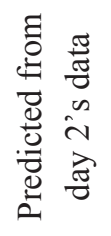 & 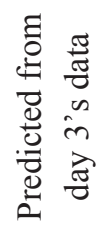 \\
\hline Day1 & 16.27 & 19.35 & & \\
\hline Day2 & 20.22 & 19.36 & 21.28 & \\
\hline Day3 & 23.99 & 19.37 & 21.29 & 22.47 \\
\hline
\end{tabular}

Table 4 - Validation of the model 2 with seven variables $\left(C, n, p, T_{a}, \sin \delta, r, W\right)$

\begin{tabular}{|c|c|c|c|c|}
\hline 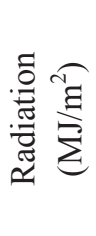 & 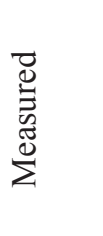 & 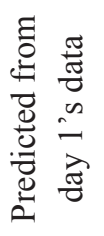 & 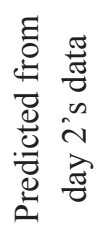 & 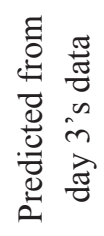 \\
\hline Day1 & 16.27 & 18.79 & & \\
\hline Day2 & 20.22 & 18.80 & 21.33 & \\
\hline Day3 & 23.99 & 18.81 & 21.35 & 22.37 \\
\hline
\end{tabular}

Table 5 - Validation of the model 3 with six variables $\left(C, n, p, T_{a}, \sin \delta, r\right)$

\begin{tabular}{|c|c|c|c|c|}
\hline 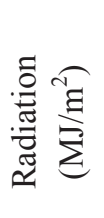 & 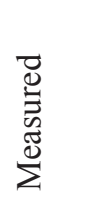 & 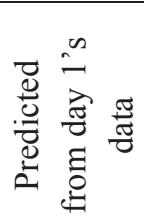 & 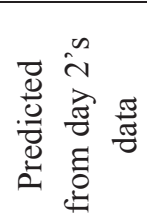 & 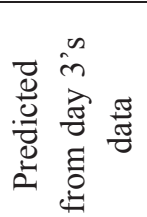 \\
\hline Day1 & 16.27 & 18.98 & & \\
\hline Day2 & 20.22 & 18.99 & 21.56 & \\
\hline Day3 & 23.99 & 19.00 & 21.57 & 22.52 \\
\hline
\end{tabular}


Table 6 - Validation of the model 4 with six variables $\left(C, n, p, T_{a}, \sin \delta, W\right)$

\begin{tabular}{|c|c|c|c|c|}
\hline : & 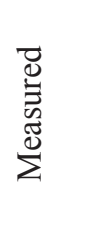 & 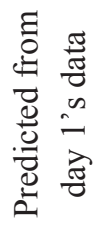 & 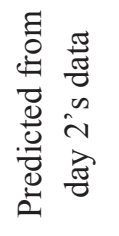 & 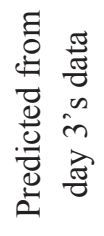 \\
\hline Day1 & 16.27 & 18.51 & & \\
\hline Day2 & 20.22 & 18.52 & 21.05 & \\
\hline Day3 & 23.99 & 18.53 & 21.06 & 22.09 \\
\hline
\end{tabular}

Table 7 - Validation of the model 5 with six variables $\left(C, n, T_{a}, \sin \delta, r, W\right)$

\begin{tabular}{|c|c|c|c|c|}
\hline 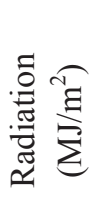 & 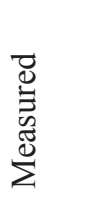 & 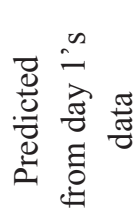 & 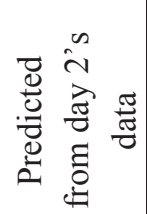 & 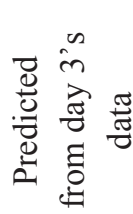 \\
\hline Day1 & 16.27 & 18.79 & & \\
\hline Day2 & 20.22 & 18.80 & 21.25 & \\
\hline Day3 & 23.99 & 18.81 & 21.26 & 22.29 \\
\hline
\end{tabular}

Table 8 - Validation of the model 6 with five variables $\left(C, n, p, T_{a}, \sin \delta\right)$

\begin{tabular}{|c|c|c|c|c|}
\hline 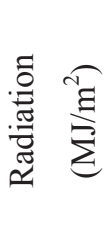 & 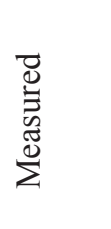 & 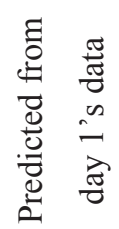 & 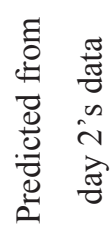 & 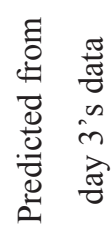 \\
\hline Day1 & 16.27 & 18.72 & & \\
\hline Day2 & 20.22 & 18.73 & 21.29 & \\
\hline Day3 & 23.99 & 18.74 & 21.30 & 22.27 \\
\hline
\end{tabular}

Table 9 - Validation of the model 7 with five variables $\left(C, n, T_{a}, \sin \delta, r\right)$

\begin{tabular}{|c|c|c|c|c|}
\hline 胥 & 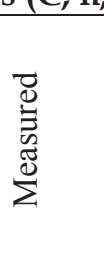 & 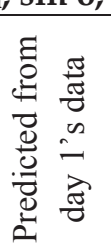 & 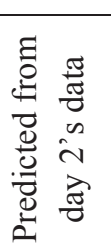 & 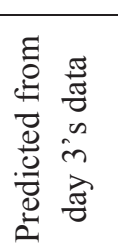 \\
\hline Day1 & 16.27 & 18.92 & & \\
\hline Day2 & 20.22 & 18.93 & 21.41 & \\
\hline Day3 & 23.99 & 18.94 & 21.42 & 22.37 \\
\hline
\end{tabular}

Table 10 - Validation of the model 8 with four variables $\left(C, n, T_{a}, \sin \delta\right)$

\begin{tabular}{|c|c|c|c|c|}
\hline & 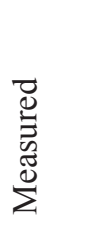 & 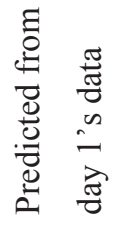 & 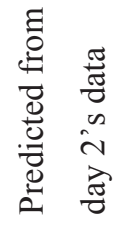 & 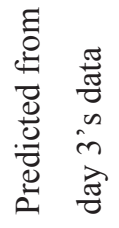 \\
\hline Day1 & 16.27 & 18.66 & & \\
\hline Day2 & 20.22 & 18.67 & 21.13 & \\
\hline Day3 & 23.99 & 18.69 & 21.14 & 22.12 \\
\hline
\end{tabular}

\section{Recommendations and Conclusion}

The study was based on data collected from an existing solar power plant at Sooriyawewa and the Automated Weather Station (AWS) of meteorological department of Sri Lanka. Multiple linear regressions was applied on the data set and several models were obtained which describe the daily solar radiation from other identified parameters. (sunshine hours, precipitation, cloud cover, ambient temperature, sine of declination angle, relative humidity, wind speed and gust speed).

The proposed models gave acceptably high $\mathrm{R}^{2}$ values as well as other statistical indicators. Therefore, it is possible to consider these proposed models provide sufficiently accurate predictions for solar radiation.

An effort was not made to compare between the models because intention was to develop models based on parameters for which predictions are available for a given site. It could be observed that effects of sunshine hours, cloud cover, ambient temperature and declination angel on the solar radiation are more significant in all the models.

Sri Lanka being an island small in size $(65,000$ $\left.\mathrm{km}^{2}\right)$ and small latitudinal extent $\left(<4^{\circ}\right)$, the model may form the basis for more comprehensive solar radiation prediction models for other areas in Sri Lanka [2].

In order to further improve the accuracy of the results, it is recommended to collect data for a longer period of time to build models described in this paper. 


\section{References}

[1] Dave Renne, Ray george, Bill Marion, Chris Gueymard, Donna Heimiller, "Solar Resource Assessment for Sri Lanka and Maldives, National Renewable Energy Laboratory, U.S. Department of Energy NREL/TP-710-34645, 2003.

[2] Punyawardena, B.V.R., and Don Kulasiri, "Stochastic Simulation of Solar Radiation from Sunshine Duration in SriLanka", Centre for computing and biometrics, Lincoln University, Research paper No. 96/06, September, 1996.

[3] Peiris, T. S. G. and Thattil, R. O., "An 'Alternative' Model to Estimate Solar Radiation”, COCOS 10, 26-34, Department of crop science, University of Peradeniya, Sri Lanka, 1994-1995.

[4] Harlan, H., Bengtson, Solar Energy Fundamentals, Course No. M04-018.

[5] Inci Turk Togrul, "Estimation of Solar Radiation from Angstroms Coefficients by using Geographical and Meteorological Data in Bishkek, Kyrgystan", Isi Billimi ve Teknigi Dergisi 29,2,99-108, Chemical Engineering Department, Engineering Faculty, Afyon Kocatepe University, 2009

[6] Scharmer, K., and Greif, J., “European Solar Radiation Atlas, Vol 1: Fundamentals and Maps", Paris, 2000.

[7] Bose, A., Multiple Linear Regression, BIMTECH, October 2009.

[8] Allin Cottrell, Regression Analysis: Basic Concepts, 2011.

[9] Muzathik, A. M., Nik, W. B. W., Ibrahim, M. Z., Samo, K. B., Sopian, K., and Alghoul, M. A., "Daily Global Solar Radiation Estimate Based on Sunshine Hours" , International Journal of Mechanical and Materials Engineering (IJMME), Vol. 6, No. 1.75-80, Malaysia, 2011. 
